\title{
Morphological variation of plants on the uprising islands of northern Russia
}

\author{
Anna Serebryanaya ${ }^{1} \&$ Alexey Shipunov ${ }^{2, *}$
}

\author{
1) San Francisco State University, 1600 Holloway Avenue, San Francisco, CA 94132, USA \\ 2) Encyclopedia of Life, Marine Biological Laboratory, Woods Hole, MA 02543, USA (corresponding \\ author'se-mail: ashipunov@eol.org)
}

Received 20 May 2008, revised version received 16 Feb. 2009, accepted 24 Feb. 2009

\begin{abstract}
Serebryanaya, A. \& Shipunov, A. 2009: Morphological variation of plants on the uprising islands of northern Russia. - Ann. Bot. Fennici 46: 81-89.
\end{abstract}

The purpose of our study was to test whether any significant morphological differences exist between island and mainland plant populations of the north European White Sea. Six polymorphic species were studied: Atriplex nudicaulis (Chenopodiaceae), Euphrasia wettsteinii (Orobanchaceae), Achillea millefolium (Asteraceae), Parnassia palustris (Parnassiaceae), Potentilla egedii (Rosaceae) and Rhodiola rosea (Crassulaceae). Based on the multivariate analyses of our data, we found 10 cases where differences between island and mainland populations are best explained by the existence of shortscale evolutionary processes. These results suggest that plant populations on islands of recent origin may display local morphological divergence in a short evolutionary time frame.

Key words: evolution, islands, plant morphology, variation, White Sea

\section{Introduction}

Islands have been considered natural laboratories for exploring the evolutionary processes from the times when Charles Darwin discovered finch diversity on the Galapagos Islands, which lead him to the idea of geographical speciation (Darwin 1839, Grant 1996, Emerson 2002, Whittaker \& Fernandez-Palacios 2007). There are multiple examples of recent evolutionary studies on islands, and in numerous cases plants are the main objects of research (Soejima et al. 1994, Barrett et al. 1996, Ito et al. 1998, Baldwin \& Sanderson 1998, Stuessy 1998, Ballard 2000, Stuessy et al. 2006).
It is known that small-scale morphological differentiation is often subject to natural selection (Gurevitch 1992, Linhart \& Grant 1996) and microevolution rates are sometimes surprisingly high (Cody \& Overton 1996, Van Vuren \& Bowen 1999, Bone \& Farris 2001). Of particular importance to our study is that there is a significant geographical variation in certain morphological characteristics of plants (Andersson 1991, Andersson 1995, Widen 2003, Barrera \& Walter 2006). Moreover, many aspects of islands' flora are greatly influenced by island surface area and its remoteness from the mainland (McMaster 2005, Kalmar \& Currie 2006). In general, morphological differences could happen due to 


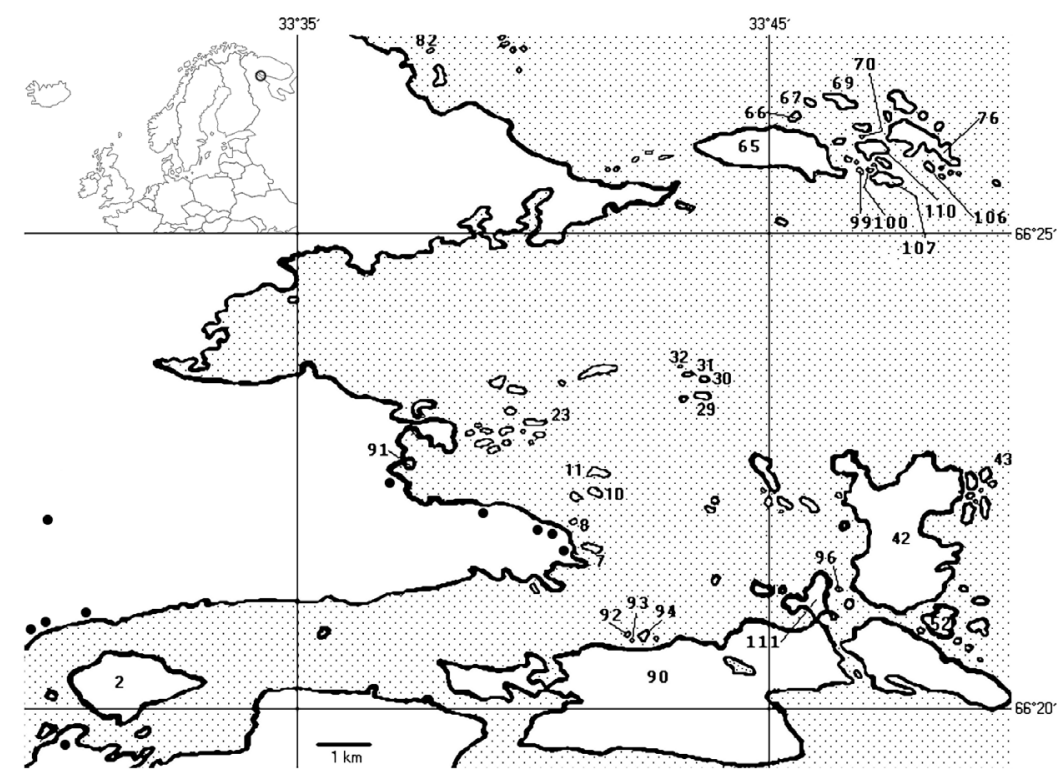

Fig. 1. Map of the region, with designations of all investigated islands. Names of islands with "contrasts" are set in boldface; dots indicate locations of mainland samples. Inset in the upper left corner shows the part of Europe enlarged in the main map. Islands of the Odinokie Ludi archipelago: 29 = Boljshaya Odinokaya Luda, $30=$ Malaya Odinokaya Luda, 31 = Srednyaya Odinokaya Luda, $32=$ Ochenj Odinokaya Luda. Islands of the Kem'-Ludy archipelago: $65=$ Kemludskij, $66=$ Perejma, $67=$ Korablik, $69=$ Korzhnichiha, $70=$ Sinopchiha, 76 = Bol'shoj Asaf'ev, $99=$ Zhguchij, $100=$ Matrasik. Other islands: $2=$ Oleniyj, $7=$ Ivanjkov, $8=$ Rihzhenjkiyj, 10 = Skeletov, $11=$ Drakonchik, $23=$ Izbyanaya Luda, $42=$ Sidorov, $43=$ Cherepakha, $49=$ Vihsokaya Luda, $52=$ Vichennaya Luda, $82=$ Morschovec, $90=$ Keret', $91=$ Pryaostrov, $92=$ Pizhmyak, $93=$ Kivsyak, $94=$ Lahtak, $96=$ Zvezdov, 106 = Gusinyj, 107 = Zelenyj, 110 = Izbyanoj, 111 = Bolshoj Andronin.

selection and/or genetic drift (Abdelkrim 2005, Stuessy et al. 2006), and should correlate with the remoteness of the island as a measure of isolation (Mayr 1942, Grant 1996). They could also be caused by phenotypic variation but that can be excluded (at least partly) by using properly selected species and parameters, multiple observations, and investigations of local variability.

To investigate the geographic impact on plant morphology, we chose to study the uprising islands and islets of Chupa and Kiv gulfs and Kem'-Ludy archipelago of the big Kandalaksha gulf of the north Russian White Sea (Fig. 1). The history of these islands is unique. During the last ice age (12-15 000 years ago) the entire northern Europe was covered with ice, which was around $3 \mathrm{~km}$ deep and caused enormous pressure on the Earth's crust. As a result, the whole region of the future White Sea sank to form a depression of 0.2-0.3 km deep (Hattestrand \& Clark 2007). Later, when the climate became warmer, the ice melted, forming the sea and its islands. As a con- sequence of the former depression, many islands are still rising today with a speed of approximately $5-8 \mathrm{~mm}$ per year, and new islands are constantly appearing (Koshechkin 1979, Shipunov \& Abramova 2006).

The flora of these islands is relatively poor (Shipunov \& Abramova 2006) since the majority of plants belong to the northern taiga. Distant islands are covered with tundra-like flora mainly due to strong winds (Breslina 1987). A variety of plants that occur both on the mainland and the islands of the White Sea were noted to be taxonomically diverse (Sokoloff \& Filin 1996). We chose six herbaceous (two annual and four perennial) species that are common to the studied area and have the reliable taxonomic diversity under the species level: Atriplex nudicaulis (Chenopodiaceae), Euphrasia wettsteinii (Orobanchaceae), Achillea millefolium (Asteraceae), Parnassia palustris (Parnassiaceae), Potentilla egedii (Rosaceae) and Rhodiola rosea (Crassulaceae). For example, Atriplex species are extremely 
variable, both morphologically and genetically, and some of their characters can be affected by the environment conditions (Ortiz-Dorda et al. 2005, Bouda 2006). Euphrasia is also known for its high morphological variability, especially in northern regions (Swann 1973, Yeo 1978, Gussarova 2005). Many of Achillea species are taxonomically problematic, with bottleneck effects having a large impact on variation in several species, especially among those in isolated habitats (Saukel \& Langer 1990, Guo et al. 2004, 2005, 2008). Parnassia palustris can be diploid and tetraploid (the last form occurs specifically in the northern Europe and alpine habitats), both types show morphological variation, and are often confused with other species (Borgen \& Hultgard 2003). Similar situations exist in Potentilla egedii (Kamelin 2001) and Rhodiola rosea (Uhl 1952, Sokoloff \& Filin 1996).

Thus, the high variability of the chosen plant species set makes them a reliable tool to study plant variability on islands. Consequently, the goal of our research was to check if plants evolve differently on the mainland as compared with the islands, and if the geographical characteristics of the islands (such as height and surface area) influence these changes.

\section{Materials and methods}

Typically at least one population from each island was studied. Each sample consisted of approximately 20-25 plants from every population (topographically isolated group of plants). On each plant 7-10 morphological characteristics were measured, and in most cases we used parameters that were already known as variable and/or helpful for distinguishing plants on the intra-species level (Swann 1973, Yeo 1978, Saukel \& Langer 1990, Sokoloff \& Filin 1996, Kamelin 2001, Gussarova 2005).

In addition to the classical morphological characteristics, in two cases (Atriplex and Rhodiola) we used leaf contours of the largest leaf for geometric morphometry, namely, thin plate spline (TPS) analysis of the leaf shape diversity between populations (Adams et al. 2004, Shipunov \& Bateman 2005). The leaf shapes of Atriplex and Rhodiola were described by 8 or
6 landmarks, respectively, situated on the bend points of the leaf contour. The coordinates of landmarks were written to a data file with the help of a screen digitizer tpsDig (Rohlf 2006). The relative warps, characterizing the degree of differences between the specimen and consensus configuration, were calculated with tpsRelw (Rohlf 2007) and then used in the overlap analysis (see below). Original coordinates were normalized using the Procrustes fit method $(\alpha=0)$.

To explore the variation of plant species within one island we performed a thorough sampling on some islands for Achillea and Rhodiola. We tried to choose multiple sites that belonged to different habitats and were most distant from each other. This was done to eliminate the possibility of small-scale impacts of local conditions on the sample populations. The same overlap analysis (see below) was used with this kind of data.

The analytical part of our study started with the comparison of overlaps derived from principal components analysis (PCA) for scaled data (we used scaled data to eliminate the effects of the different nature of parameters used). For each species, extreme points on the PCA graph(s) of most informative principal components (usually PC1 and PC2, sometimes also PC3) were used for plotting convex hulls, which depicted different populations (see Fig. 2). In most cases, polygons were intersected and therefore let us calculate the percentage of overlap between each pair of polygons. Since we used polygons instead of original points, we were able to take into account the whole norm of reaction and identify the sampling effect. Thus, overlap coefficients were calculated for all pairs of populations, along with the mean overlap for each population as a measure of morphological remoteness. We used 20\%-25\% of mean overlap as a boundary value for initiating further investigations with the population. In several cases, the overlap was adjusted by removing obvious outliers from the PCA. In addition to the PCA, we used multi-dimensional scaling (MDS) and linear discriminant analysis (LDA), but the results of these attempts were not significantly different. In the cases of Rhodiola and Atriplex, two different PCA (with classical and geometric morphometry parameters) were performed, and two separate series of overlap were calculated. 


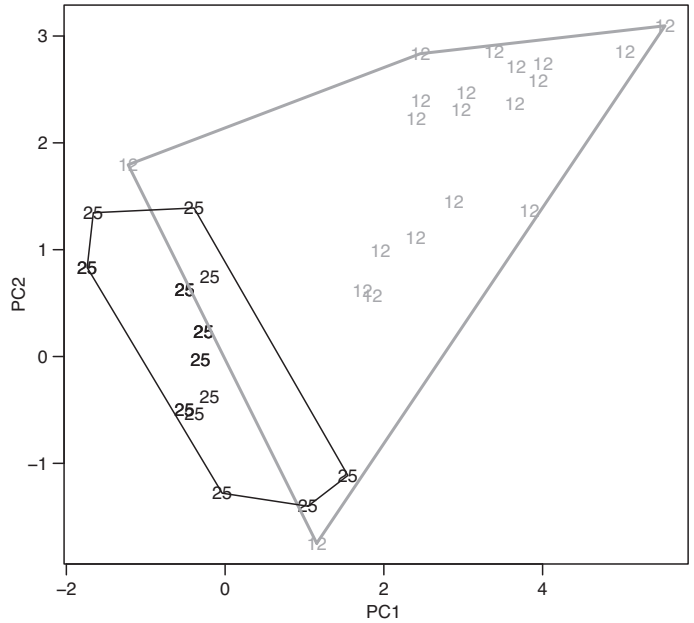

Fig. 2. An example of the overlap analysis for a PCA plot. Two populations of Achillea millefolium are represented: no. 12 is from island contrast whereas no. 25 is the population from mainland. Since the overlap is an asymmetric measure (calculated as Overlap ${ }_{a, b}=$ Area $_{\mathrm{a}} /$ Area $_{\mathrm{a}}$ ), overlap values in this case are $12.64 \%$ and $40.71 \%$, respectively. The mean overlap of all cases is $26.68 \%$.

To obtain statistical support for the differences between mainland and island populations and to find characters with significant variation, we performed multivariate and partial ANOVA analyses for selected data (all mainland and contrasting island populations were selected) with "mainland $v s$. island" as an independent variable.

To find out if the differences between island and mainland populations correlated with an island's parameters (altitude, area, and distance from mainland) we used Gower distances calculated between island and mainland populations on the base of median character values. Next, the Spearman rank correlation tests were used to obtain values and statistical significance of correlations between distances and island parameters. We employed this analysis twice: for all characters measured, and for characters selected from MANOVA results.

For all statistical calculations, R statistical environment and language ( $\mathrm{R}$ Development Core Team 2007) was used.

\section{Results}

In total, over 2800 plants were measured from 145 populations (topographically isolated groups of plants), taken from 33 islands and 32 locations on mainland (Fig. 1 and Table 1). In total, 51 morphological characteristics were measured (see Table 2). Several plants from each location were put into a herbarium.

Among the populations with a low overlap percentage, we searched for cases in which the difference in morphology from mainland populations correlated with the geographic position of the studied island. We refer to those as "island contrasts" and hereafter use the following abbreviations for the three different cases:

A: when population(s) from one island differed from mainland populations;

B: when the difference existed between populations of neighboring islands (i.e., parts of one archipelago) and mainland; and

$\mathrm{C}$ : when we observed differences between main-

Table 1. Numbers of investigated units for each species.

\begin{tabular}{|c|c|c|c|c|}
\hline Species & $\begin{array}{l}\text { Number of } \\
\text { investigated } \\
\text { plants }\end{array}$ & $\begin{array}{l}\text { Number of } \\
\text { investigated } \\
\text { populations }\end{array}$ & $\begin{array}{l}\text { Number of } \\
\text { investigated } \\
\text { islands }\end{array}$ & $\begin{array}{l}\text { Islands investigated in each case } \\
\text { (see Fig. } 1 \text { for island names and } \\
\text { locations) }\end{array}$ \\
\hline Achillea millefolium & 573 & 32 & 16 & $\begin{array}{l}2,7,10,11,29,31,32,42,67,69,76 \\
91,99,106,107,110\end{array}$ \\
\hline Atriplex nudicaulis & 488 & 25 & 21 & $\begin{array}{l}2,7,8,29,30,31,42,43,49,52,65 \\
66,76,90,91,92,93,94,96,110,111\end{array}$ \\
\hline Euphrasia wettsteinii & 608 & 31 & 18 & $\begin{array}{l}7,8,10,23,29,31,32,42,43,67 \\
69,70,91,99,100,106,107,110\end{array}$ \\
\hline Parnassia palustris & 295 & 15 & 10 & $8,31,42,49,65,66,76,82,90,110$ \\
\hline Potentilla egedii & 147 & 8 & 1 & 76 \\
\hline Rhodiola rosea & 691 & 34 & 16 & $\begin{array}{l}7,8,29,30,31,43,49,52,66,70 \\
76,82,94,96,106,110\end{array}$ \\
\hline
\end{tabular}


land populations and groups of populations from distant islands.

The most reliable types are $\mathrm{A}$ and $\mathrm{B}$, where population(s) from one island or densely located group of islands have a small overlap with all the studied mainland populations of a certain species. This is a putative evidence of evolutionary divergence. Type $\mathrm{C}$ may be the results of parallel evolution and/or colonization.

In most cases, the average overlap values for the entire species ranged between $30 \%$ and $40 \%$. The only exception were the results of geometric morphometry, in which these values were $49.29 \%$ and $51.02 \%$ (for Atriplex and Rhodiola leaf contours, respectively). Therefore, in both cases of geometric morphometry there was not enough of an overlap to select populations, because all the values were well above $25 \%$.

The thorough sampling (multiple sites on each island, data from different years pooled together) resulted in high overlap values for all investigated populations from one island: 44.15\% for six Achillea populations from one island, and 39\%-73\% for eighteen Rhodiola populations from three different islands.

Based on the analysis of individual populations, 19 populations of interest with the lowest overlap values were chosen. In two cases (both with Euphrasia) the construction of reliable contrasts was impossible, because other populations from the same island had a significantly higher overlap. As a result, only 17 populations were used in island contrasts (Table 3). Most of the contrasts were of type A, but in the case of Parnassia only type $\mathrm{C}$ was found. The most distinct populations were located on the Kem'Ludy and Odinokie Ludy archipelagos, but not on all studied islands. All islands with contrasts (with the exception of Ochen' Odinokaya Luda, no. 32, see Fig. 1) were different from the other studied islands because of their relatively large size (median area $167000 \mathrm{~m}^{2}$ vs. $34574 \mathrm{~m}^{2}$, Wilcoxon rank test $=58, p=0.05833)$ and greater distance from mainland $(4616 \mathrm{~m}$ vs. $2200 \mathrm{~m}$, Wilcoxon rank test $=54, p=0.0527)$, whereas the altitudes were not significantly different $(12.6 \mathrm{~m} v s .7 .93 \mathrm{~m}$, Wilcoxon rank test $=77, p=$ 0.2754). The largest number of island contrasts (4) belong to Bol'shoj Asaf'ev island (no. 76,
Table 2. Morphological characteristics measured for each plant species. Characters with significant differences (with $p<0.01$ ) in all partial ANOVA analyses for island contrasts are set in boldface.

Species and characters measured

Achillea millefolium

Number of stem leaves

Length of first stem leaf $(\mathrm{mm})$

Number of first order lobes on the first stem leaf

Length of maximal first order lobe $(\mathrm{mm})$

Width of maximal first order lobe $(\mathrm{mm})$

Relative position of maximal first order lobe $(\mathrm{mm})$

Length of central flowering head $(\mathrm{mm})$

Length of maximal ligule $(\mathrm{mm})$

Width of maximal ligule $(\mathrm{mm})$

Atriplex nudicaulis

Length of petiole of the largest leaf $(\mathrm{mm})$

Length of maximal leaf $(\mathrm{mm})$

Width of maximal leaf $(\mathrm{mm})$

Relative position of maximal leaf width $(\mathrm{mm})$

Length of largest bract ( $\mathrm{mm}$ )

The level of accretion of bract pair (points)

Abundance of bract teeth (points)

Euphrasia wettsteinii

Length of main stem (mm)

Number of first order branches

Number of main nodes

Length if internode under lower bract $(\mathrm{mm})$

Length of lower bract $(\mathrm{mm})$

Width of lower bract $(\mathrm{mm})$

Number of teeth on lower bract

Length of corolla of flower adjacent to lower

bract $(\mathrm{mm})$

Parnassia palustris

Height of flower stalk $(\mathrm{mm})$

Position of upper bract leaf $(\mathrm{mm})$

Length of upper bract leaf $(\mathrm{mm})$

Width of upper bract leaf $(\mathrm{mm})$

Position of width of upper bract leaf $(\mathrm{mm})$

Length of sepal $(\mathrm{mm})$

Width of sepal $(\mathrm{mm})$

Form of sepal apex (points)

Length of petal ( $\mathrm{mm})$

Number of lobes on staminode

Potentilla egedii

Length of maximal leaf $(\mathrm{mm})$

Relative position of maximal leaflet $(\mathrm{mm})$

Length of maximal leaflet $(\mathrm{mm})$

Width of maximal leaflet $(\mathrm{mm})$

Amount of hairs on maximal leaflet (points)

Type of hairs on maximal leaflet (points)

Length of maximal tooth on the leaflet $(\mathrm{mm})$

Distance from tooth base to midrib of the

leaflet $(\mathrm{mm})$

Type of sepal, points

Diameter of flower $(\mathrm{mm})$

Rhodiola rosea

Length of maximal leaf $(\mathrm{mm})$

Width of maximal leaf $(\mathrm{mm})$

Relative position of maximal leaf width $(\mathrm{mm})$

Width of leaf base of maximal leaf $(\mathrm{mm})$

Number of bracts

Length of sepal (mm)

Position (bend level) of bracts (points) 
see Fig. 1), and among plants - to Achillea and Atriplex (4 in each case).

From 51 characters measured, 19 were significantly different in all partial ANOVA analyses for island contrasts (Table 2). All MANOVA analyses for contrasts were significant (Table 3), whereas Wilks' $\lambda$ showed that $\sim 50 \%$ or more of variation was explained by the island vs. mainland factor in 8 of 10 cases, with notable exception for contrasts from Euphrasia and Potentilla (Table 3).

In most cases, coefficients of correlation were not high, and correlations for the selected characters were higher than for all characters (Table 4). Coefficients for Euphrasia were negative in all cases (and significant for altitudes and distances), whereas all other significant coefficients were positive. In the case of Achillea, no significant correlations were found. The highest and most stable correlations (with both area and altitude of islands) were in the case of Atriplex.

\section{Discussion}

From 113 island populations studied, we found 17 that were morphologically different from all the other studied populations of the same species. According to the geographical distribution, these 17 populations were grouped into 10 island contrasts. Most of these contrasts belong to two groups of relatively big and remote islands. Some of these islands host more than one (in some cases up to 4) contrasts. Moreover, some positive correlations were found between an island age (represented by surface area and altitude) and its remoteness from the mainland, on the one hand, and morphological distances in island and mainland populations, on the other hand. Between populations of $A$. millefolium and $R$. rosea collected on the same island, no significant differences were found by the thorough sampling. We believe that the observed island contrasts represent early stages of local geo-

Table 3. Results of the MANOVA analyses for selected island contrasts. For the numbers of islands, see Fig. 1. All differences significant at $p<0.001$.

\begin{tabular}{lclc}
\hline Species & Islands in the contrast & Type of contrast & Wilks' $\lambda$ \\
\hline Achillea millefolium & 29,32 & close islands vs. mainland & 0.3874 \\
Achillea millefolium & $76,107,110$ & close islands vs. mainland & 0.533 \\
Atriplex nudicaulis & 29 & island vs. mainland & 0.5219 \\
Atriplex nudicaulis & 65 & island vs. mainland & 0.237 \\
Atriplex nudicaulis & 76,110 & close islands vs. mainland & 0.289 \\
Euphrasia wettsteinii & 106 & island vs. mainland & 0.6649 \\
Parnassia palustris & 42,76 & distant islands vs. mainland & 0.278 \\
Potentilla egedii & 76 & island vs. mainland & 0.6642 \\
Rhodiola rosea & 30 & island vs. mainland & 0.0051 \\
Rhodiola rosea & 110 & island vs. mainland & 0.2988 \\
\hline
\end{tabular}

Table 4. Spearman rank correlations between morphological distances between island and mainland populations, and characteristics of islands. Significant correlations (at $p<0.05)$ are set in boldface.

\begin{tabular}{lccr}
\hline Species & $\begin{array}{c}\text { Correlation with } \\
\text { island altitude }\end{array}$ & $\begin{array}{c}\text { Correlation with } \\
\text { island area }\end{array}$ & $\begin{array}{c}\text { Correlation with distance } \\
\text { from island to mainland }\end{array}$ \\
\hline Achillea millefolium (all characters) & -0.164 & -0.283 & 0.316 \\
Achillea millefolium (selected characters) & 0.137 & 0.014 & -0.122 \\
Atriplex nudicaulis (all characters) & 0.383 & $\mathbf{0 . 4 5 1}$ & 0.276 \\
Atriplex nudicaulis (selected characters) & $\mathbf{0 . 4 2 2}$ & $\mathbf{0 . 5 1 0}$ & 0.211 \\
Euphrasia wettsteinii (all characters) & -0.372 & -0.264 & $-\mathbf{0 . 3 8 5}$ \\
Euphrasia wettsteinii (selected characters) & -0.365 & -0.326 & -0.005 \\
Parnassia palustris (all characters) & 0.103 & 0.224 & $\mathbf{0 . 5 5 2}$ \\
Parnassia palustris (selected characters) & 0.304 & 0.438 & $\mathbf{0 . 8 0 9}$ \\
Rhodiola rosea (all characters) & -0.336 & -0.186 & 0.279 \\
Rhodiola rosea (selected characters) & 0.455 & $\mathbf{0 . 6 3 2}$ & 0.196 \\
\hline
\end{tabular}


graphic speciation, resulting from initial colonization and subsequent selection and/or from accumulation of neutral mutations. This agrees well with the results of known studies on the morphological diversity of island and mainland plant populations (Kawakubo 1986, Andersson 1995, Cody \& Overton 1996), where the largest differences were usually observed on oldest and most remote islands (Andersson 1995, Barrett et al. 1996) and comparably fast evolutionary rates were found (Cody \& Overton 1996, Van Vuren \& Bowen 1999, Bone \& Farres 2001).

However, since plants usually have high phenotypic plasticity, we cannot exclude the possibility of observed differences being caused directly by environmental conditions. Still, we have some indirect evidence against the latter explanation. To begin with, similarity between populations within one island was high and did not significantly change across the years despite of our attempts to measure populations from most diverse environmental conditions. In addition, several studies of plant phenotypic plasticity led other authors to the conclusion that morphological diversity of size parameters coincides well with genetic diversity (Gurevitch 1988, 1992, Linhart \& Grant 1996, Housman et al. 2002, Widen \& Schiemann 2003). Even in the case of "pure" phenotypic plasticity, observed differences may be a good sign of evolutionary process (Pigliucci et al. 2006). Moreover, the recent AFLP investigations of some of our Achillea populations already revealed that plants from the most remote islands (see the "Ra1" and "Ra13" samples in Guo 2008) have the highest level of genetic divergence, and the overall genetic diversity between our samples is high (Y. Guo pers. comm.). Nevertheless, thorough molecular genetic studies along with common garden experiments are needed to provide better support for differences found.

Among ten island contrasts found, three belonged to type $\mathrm{B}$ (where populations from a group of neighboring islands collectively differ from the mainland populations). This is most likely due to either a relatively high level of interchange between neighboring islands or to one colonization event. Only one island contrast of type $\mathrm{C}$ was found, and the best explanation is that this is a result of parallel selection, especially if we take into account that contrasting characters of $P$. palustris are clearly correlated with pollination (shorter flowering stalk but larger sepals, petals, and staminodes). However, the existence of multiple colonization routes for P. palustris (Borgen \& Hultgard 2003) increase the possibility of observing different "waves of colonization," where "oldest" plants occupy the most remote islands. The high correlation (Spearman $\rho=0.809, p=0.005$ ) between geographical and morphological distances provides additional support for the latter explanation.

It should be noted that the studied species are unequal. Achillea millefolium, Atriplex nudicaulis and Rhodiola rosea demonstrated most of the evidence of possible evolutionary processes. These species have the maximal numbers of island contrasts and the highest age/diversity correlations. Among them, the diversity of A. millefolium is best studied (Guo et al. 2004, 2005, 2008). Since A. millefolium aggregate includes different phases of speciation (Guo et al. 2005, 2008) it should be easy to find the traces of very recent evolutionary events. Atriplex nudicaulis and $R$. rosea are much less studied. Nevertheless, complex taxonomic situations in both cases (Uhl 1952, Sokoloff \& Filin 1996, Ortiz-Dorda et al. 2005, Bouda 2006) could be the results of similar complexity.

Among the studied species four (A. nudicaulis, E. wettsteinii, P. palustris and $R$. rosea) belong to the bird-dependent, "ornithophilous" (in terms of Breslina 1987) plants, because their distribution correlates well with the distribution of sea birds, especially gulls. In addition, first two species are annuals, and A. nudicaulis is a wind-pollinated plant and also the only hydrochorus plant (fruits dispersed by sea currents). However, we cannot prove any relation between these features and patterns of distribution of our island contrasts.

Euphrasia wettsteinii seems to be the least reliable species for a study like ours. We found only one contrast, and two other potential contrasts were spoiled by the presence of much less divergent populations from the same islands. Moreover, correlations between diversity and age were negative, supporting the view that in the case of $E$. wettsteinii the observed differences were accidental. Unfortunately, the prelim- 
inary AFLP analysis of our Euphrasia samples was unsuccessful because of DNA extraction problems (G. Gussarova pers. comm.). Similarly, in our geometric morphometry approach, leaf shape of $A$. nudicaulis and $R$. rosea did not provide valuable information. It is hard to say whether $P$. egedii was a good candidate for plant diversity research, since only one island population was studied, and this one was morphologically different from all the 7 mainland populations that were investigated.

Overall, we believe that changes in plant morphology we observe for the uprising islands as compared with the mainland represent early stages of small-scale evolutionary processes. These changes have likely been caused by a colonization effect, followed by selection on the islands. The future of island contrasts remains unclear. In theory, some of the island populations can evolve further and become separate species. However, geological processes in the region are running fast and in the future many of our islands will merge (many of Kem'-Ludy islands are already connecting during low tides: Shipunov \& Abramova 2006) and finally connect with the mainland. This will result in the fading and mutual disappearance of isolation barriers, and then probably with the elimination of existing morphological differences. Nevertheless, the rising islands of the White Sea will remain a natural laboratory for studying short-scale evolutionary processes as long as they exist.

\section{Acknowledgements}

We are cordially grateful to all members of the White Sea Expedition of Moscow South-West High School (headed by S. Glagolev), who collected all the material in the field; to specialists who helped us in plant identification: D. Sokoloff, G. Gussarova, A. Sukhorukov and N. Tzvelev; to E. Altschuler, O. Kudina, M. Lyovina and D. Vasyukov who assisted on the initial stages of statistical processing; and to P. Volkova and P. Petrov for their valuable comments on the manuscript.

\section{References}

Abdelkrim, J., Pascal, M. \& Samadi, S. 2005: Island colonization and founder effects: the invasion of the Guadeloupe islands by ship rats (Rattus rattus). - Molecular
Ecology 14: 2923-2931.

Adams, D. C., Rohlf, F. J. \& Slice, D. E. 2004: Geometric morphometrics: ten years of progress following the "Revolution". - Italian Journal of Zoology 71: 5-16.

Andersson, E. 1995: Age-related morphological differentiation among populations of Dactylorhiza traunsteineri (Orchidaceae) in eastern Sweden. - Nordic Journal of Botany 15: 127-137.

Andersson, S. 1991: Geographical variation and genetic analysis of leaf shape in Crepis tectorum (Asteraceae). - Plant Systematics and Evolution 178: 247-258.

Baldwin, B. G. \& Sanderson, M. J. 1998: Age and rate of diversification of the Hawaiian silversword alliance (Compositae). - Proceedings of the National Academy of Sciences 95: 9402-9406.

Ballard, H. E. Jr. \& Sytsma, K. J. 2000: Evolution and biogeography of the woody hawaiian violets (Viola, Violaceae): arctic origins, herbaceous ancestry and bird dispersal. - Evolution 54: 1521-1532.

Barrera, E. \& Walter, H. S. 2006: Wind effects on leaf morphology for the mangrove Conocarpus erecta at an oceanic island from the Mexican Pacific Ocean. - Revista Chilena de Historia Natural 79: 451-463.

Barrett, S. C. H., Emerson, B. \& Mallet, J. 1996: The reproductive biology and genetics of island plants [and discussion]. - Philosophical Transactions, Biological Sciences 351: 725-733.

Bone, E. \& Farres, A. 2001: Trends and rates of microevolution in plants. - Genetica 112-113: 165-182.

Borgen, L. \& Hultgard, U.-M. 2003: Parnassia palustris: a genetically diverse species in Scandinavia. - Journal of the Linnean Society of London, Botany 142: 347-372.

Bouda, S., Haddioui, A., Baaziz, M., Del Campo, F. F. \& Hernandez, L. E. 2006: Genetic diversity characterization of genus Atriplex using RAPD markers. - In: Baaziz, M., Alif, N., Benjouad, A., Boudyach, E. H., Brakez, Z., Elantri, S., Essamadi, A., Fares, K., Hakkou, A., Hatimi, A., Hmyene, A., Idrissi-Hassani, L. M., Serghini, M. A., Tahrouch, S. \& Yacoubi, B. (eds.), Congrés International de Biochimie, Agadir, 9-12 May 2006: 64-68. Universite Ibn Zohr, Agadir, Maroc.

Breslina, I. Р. [Бреслина И. П.] 1987: [Plants and sea birds of sea islands of Kola subarctic region]. — Nauka, Leningrad. [In Russian].

Cody, M. L. \& Overton, J. Mc. C. 1996: Short-term evolution of reduced dispersal in island plant populations. - The Journal of Ecology 84: 53-61.

Darwin, C. 1839: Narrative of the surveying voyages of His Majesty's Ships Adventure and Beagle between the years 1826 and 1836, describing their examination of the southern shores of South America, and the Beagle's circumnavigation of the Globe. - Journal and remarks vol. 3, Henry Colburn, London.

Emerson, B. C. 2002: Evolution on oceanic islands: molecular phylogenetic approaches to understanding pattern and process. - Molecular Ecology 11: 951-966.

Grant, P. R. (eds.) 1996: Evolution on islands. — Oxford University Press, Oxford.

Guo, Y., Ehrendorfer, F. \& Samuel, R. 2004: Phylogeny and systematics of Achillea (Asteraceae-Anthemideae) inferred from $n r$ ITS and plastid $t r n \mathrm{~L}-\mathrm{F}$ DNA sequences. 
- Taxon 53: 657-672.

Guo, Y., Saukel, J., Mittermayr, R. \& Ehrendorfer, F. 2005: AFLP analyses demonstrate genetic divergence, hybridization, and multiple polyploidization in the evolution of Achillea (Asteraceae-Anthemideae). - New Phytologist 166: 273-290.

Guo, Y., Saukel, J. \& Ehrendorfer, F. 2008: AFLP trees versus scatterplots: evolution and phylogeography of the polyploid complex Achillea millefolium agg. (Asteraceae). - Taxon 57: 153-169.

Gurevitch, J. 1988: Variation in leaf dissection and leaf energy budgets among populations of Achillea from an altitudinal gradient. - American Journal of Botany 75: 1298-1306.

Gurevitch, J. 1992: Sources of variation in leaf shape among two populations of Achillea lanulosa. - Genetics 130: 385-394.

Gussarova, G. L. [Гуссарова Г. Л.] 2005: [The check-list of Euphrasia (Scrophulariaceae) of Russia and adjacent states (within the limits of the former USSR)]. — Botanicheskyi Zhurnal, Russian Academy of Sciences 90: 1087-1115. [In Russian].

Hattestrand, C. \& Clark, C. D. 2007: Reconstructing the pattern and style of deglaciation of Kola Peninsula, northeastern Fennoscandian Ice Sheet. - In: Knight, P. G. (eds.), Glacier science and environmental change: 199-201. Blackwell Publishing, London.

Housman, D. C., Price, M. V. \& Redak, R. A. 2002: Architecture of coastal and desert Encelia farinosa (Asteraceae): consequences of plastic and heritable variation in leaf characters. - American Journal of Botany 89: 1303-1310.

Ito, M., Soejima, A. \& Ono, M. 1998: Genetic diversity of the endemic plants of the Bonin (Ogasawara) Islands. In: Stuessy, T. F. \& Ono, M. (eds.), Evolution and speciation of island plants: 141-154. Cambridge University Press, Cambridge.

Kalmar, A. \& Currie, D. J. 2006: A global model of island biogeography. - Global Ecology and Biogeography 15: 72-81.

Kamelin, R. V. [Камелин Р. В.] 2001: Potentilla L. - In: Tzvelev N. N. [Чвелев, Н. Н.] (ed.), Flora Europae Orientalis vol. 10: 394-452. Mir i Semya, Saint-Petersburg. [In Russian].

Kawakubo, N. 1986: Morphological variation of three endemic species of Callicarpa (Verbenaceae) in the Bonin (Ogasawara) Islands. - Plant Species Biology 1: 59-68.

Koshechkin, В. I. [Кошечкин Б. И.] 1979: [Holocene tectonics of the eastern part of Baltic platform]. — Nauka, Leningrad. [In Russian].

Linhart, Y. B. \& Grant, M. C. 1996: Evolutionary significance of local genetic differentiation in plants. Annual Review of Ecology and Systematics 27: 237-277.

Mayr, E. 1942: Systematics and the origin of species from the viewpoint of a zoologist. - Harvard University Press, Harvard.

McMaster, R. T. 2005: Factors influencing vascular plant diversity on 22 islands off the coast of eastern North America. - Journal of Biogeography 32: 475-492.
Ortiz-Dorda, J., Martinez-Mora, C., Correal, E., Simoon, B. \& Centis, J. L. 2005: Genetic structure of Atriplex halimus populations in the Mediterranean Basin. Annals of Botany 95: 827-834.

Pigliucci, M., Murren, C. J. \& Schlichting, C. D. 2006: Phenotypic plasticity and evolution by genetic assimilation. - The Journal of Experimental Biology 209: 2362-2367.

R Development Core Team 2007: R: a Language and Environment for Statistical Computing. — R Foundation for Statistical Computing, Vienna, Austria, available from URL: http://www.R-project.org.

Rohlf, F. J. 2006. tpsDig, version 2.10. — Available from http://life.bio.sunysb.edu/morph/.

Rohlf, F. J. 2007. tpsRelw: relative warps, version 1.45. Available from http://life.bio.sunysb.edu/morph/.

Saukel, J. \& Langer, R. 1990: Die Achillea millefoliumGruppe (Asteraceae) in Mitteleuropa. - Phyton 31: 185-207.

Shipunov, A. B. \& Abramova, L. A. 2006: Floristic changes on the Kem-Ludy islands (Russian White Sea, 19622004). - Bulletin of Moscow Society of Naturalists Biological Series 111: 45-56 [In Russian with English abstract].

Shipunov, A. B. \& Bateman, R. M. 2005: Geometric morphometrics as a tool for understanding Dactylorhiza (Orchidaceae) diversity in European Russia. - Biological Journal of the Linnean Society 85: 1-12.

Soejima, A., Nagamasu, H., Ito, M. \& Ono, M. 1994: Allozyme diversity and the evolution of Symplocos (Symplocaceae) on the Bonin (Ogasawara) Islands. - Journal of Plant Research 107: 221-227.

Sokoloff, D. D. \& Filin, V. R. [Соколов, Д. Д. \& Филин В. P.] 1996: [Diagnostic keys for vascular plants from the vicinities of White Sea biological station of Moscow State University]. - NEVZ FIPT, Moscow. [In Russian].

Stuessy, T. F. \& Ono, M. (eds). 1998: Evolution and speciation of island plants. - Cambridge University Press, Cambridge.

Stuessy, T. F., Jakubowsky, G., Gomez, R. S., Pfosser, M., Schlueter, Ph. M., Fer, Th., Sun, B.-Y. \& Kato, H. 2006: Anagenetic evolution in island plants. - Journal of Biogeography 33: 1259-1265.

Swann, E. L. 1973: Norfolk Euphrasiae. - Watsonia 9: 345-356.

Uhl, Ch. H. 1952: Heteroploidy in Sedum rosea (L.) Scop. Evolution 6: 81-86.

Van Vuren, D. \& Bowen, L. 1999: Reduced defenses in insular endemic plants: an evolutionary time frame. Conservation Biology 13: 211-212.

Whittaker, R. J. \& Fernandez-Palacios, J. M. 2007: Island biogeography. Ecology, evolution, and conservation. Oxford University Press, Oxford.

Widen, B. \& Schiemann, K. 2003: The pattern of variation in leaflet shape and reproductive characters in Lathyrus vernus (L.) Bernh. (Fabaceae). - Plant Systematics and Evolution 240: 41-54.

Yeo, P. F. 1978: A taxonomic revision of Euphrasia in Europe. - Botanical Journal of the Linnean Society 77: 223-334. 